\title{
Primary hydatid cyst of the round ligament: case report
}

\author{
M. Akinci, ${ }^{1}$ O. Yigitbasi, ${ }^{2}$ Z. Ergul, ${ }^{1}$ E. Olcucuoglu and H. Kulacoglu ${ }^{7}$
}

\section{Introduction}

Echinococcosis is a zoonotic infection in which the liver is the organ most frequently involved, followed by the lung and sometimes the heart, spleen, kidney and brain [1]. Hydatid cyst can be seen in almost every part of the human body [2-5]. Despite the common involvement of the liver in terms of location, only 2 cases of isolated hydatid cyst of the round ligament of the liver have been reported, first in 1985 in Italian [6] and then in 1993 in Spanish [7]. We present here the third case of round ligament hydatid cyst.

\section{Case report}

A 24-year-old male was admitted to the department of general surgery with an epigastric mass that he had noticed 3 months previously. He complained of abdominal fullness and vague pain. The patient had no other systemic disorder and no history of surgery or use of medical drug therapy. Physical examination of the patient revealed a semifixed 6 $\mathrm{cm}$ mass on the abdominal epigastric area adjacent to the right inferior ribs. There were no other positive findings at physical examination.

Abdominal ultrasound demonstrated a $6 \times 4 \mathrm{~cm}$ cystic mass between the anterior abdominal wall and anterior surface of the left hepatic lobe. There were no vesicles or necrotic areas in the cystic mass. It was reported that thelesion could be originating from the left lobe of the liver. Ultrasound also revealed a left renopelvic dilatation. Abdominal computerized tomography showed a $7 \times 4$ cm capsulated cystic mass that was being compressed by the hepatic left lobe and abdominal wall. A clear border between the liver and mass was visualized. No other lesions were seen in any part of the abdominal cavity (Figure 1).

The patient's routine laboratory tests were normal and the echinococcosis immune haemagglutination test (Dade Behring, Margurg, Germany) was negative. Before making a decision about the treatment of the cyst, the patient was referred to the department of urology. There he stated that he had recently started to experience left lumbar pain. In the urological evaluation an intravenous pyelogram confirmed dilatation of the left renal pelvis and calyx, and renal scintigraphy revealed left ureteropelvic stenosis. This ureteropelvic junction stenosis was considered to be symptomatic by the urologists and an open surgical treatment was planned.

First, the urologists performed a dismembered pyeloplasty, then the cystic lesion was approached by the

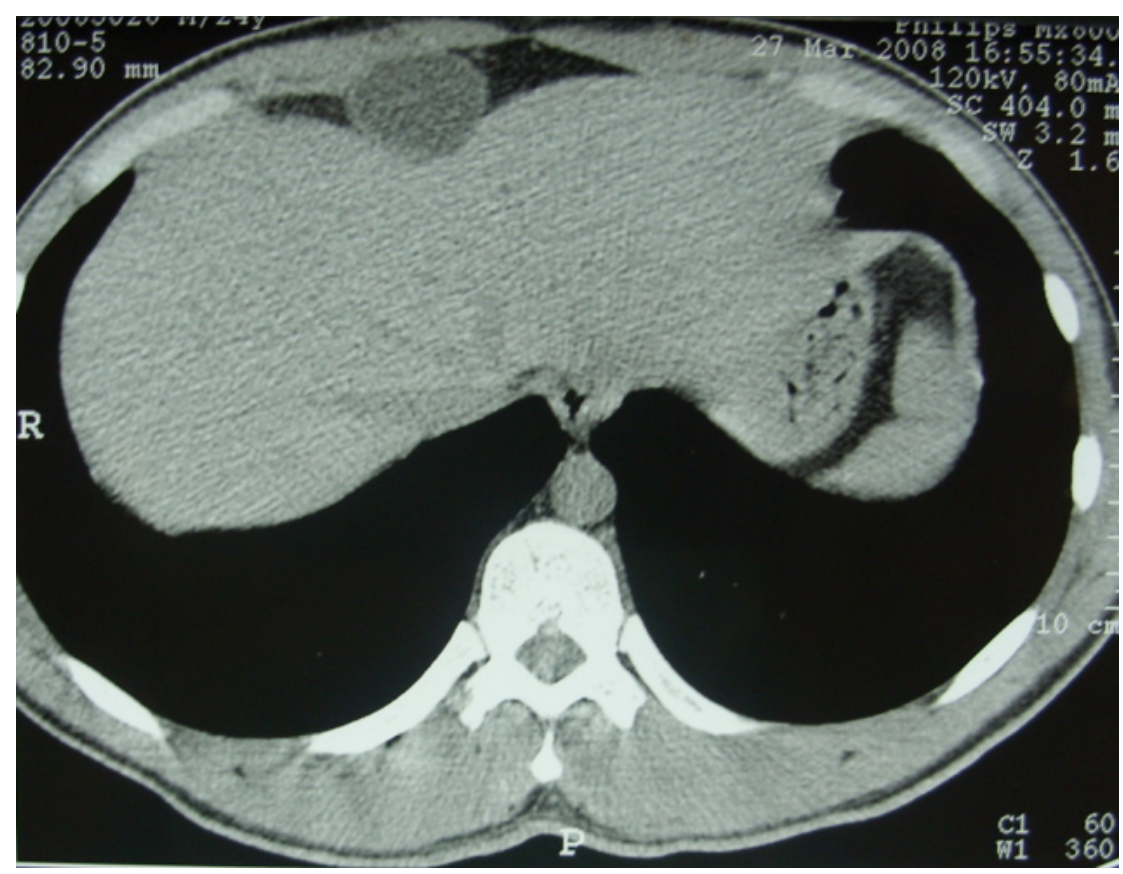

Figure 1 Hydatid cyst $(6 \times 4 \mathrm{~cm})$ between the anterior abdominal wall and the liver. A clear border is seen between the cyst and the liver $(R=$ right rectus abdominis muscle) 
general surgery team via a $10 \mathrm{~cm}$ long upper midline incision. The cyst was found to originate directly from the round ligament of the liver (ligamentum teres hepatis). The round ligament was ligated and divided and then the mass was totally excised from the abdominal wall with $1 \mathrm{~cm}$ free borders. It was a 6.5 $\times 4 \times 4 \mathrm{~cm}$ cystic mass filled with serous fluid. The capsule was creamy-white in colour with a well-circumscribed shape. The histopathological examination confirmed a hydatid cyst by demonstrating protoscolex within.

The patient's postoperative course was uneventful and he was discharged on the fourth postoperative day. Albendazole was prescribed with a dose of 2 $\times 400 \mathrm{mg} /$ day.

\section{Discussion}

Hydatid disease, caused by the larval stage ofEchinococcus granulosus, is recognized as a public health problem [8]. Turkey is an endemic region for this disease. Besides the liver and lungs, hydatid cysts with unusual locations (e.g. pancreas, spleen, kidney, intra-abdominal cavity, ovary, breast, mediastinum, chest wall, muscle, adrenal, lung, thyroid gland, anterior abdominal wall, thigh, presacral space, brain, cavernous sinus, submandibular gland, heart, pleura, retrocrural tissue, inguinal canal, bone, bile duct, soft tissue and retroperitoneum) have previously been reported from this country [2-5].

When the present case presented with an anterior mass, the lesion was considered as a possible hydatid cyst since hydatid disease is very common in Turkey and anterior abdominal hydatid cysts have been reported several times [9-11]. However, the tomographic examination noted a deeper lesion beneath the anterior abdominal wall. Therefore a pancreatic cyst, parasitic or not, was a diagnostic possibility [12].

In 2003, the World Health Organization Informal Working Group on Echinococcosis (WHO-IWGE) proposed a standardized ultrasound classification based on the active-transitional-inactive status of the cyst as suggested by its sonographic appearance [13]. In our case, ultrasonography and tomography revealed a simple cyst with well-defined borders and uniform anechoic contents. This description, according to WHOIWGE classification, is not pathognomonic for echinococcal cysts because nonparasitic cysts may have the same appearance. In addition, the haemagglutination test did not support a diagnosis of hydatid disease. However, while haemagglutination displays a very good specificity with few false positive results, it has a low sensitivity of just 50\% [14].

In fact hydatid cyst of the round ligament of the liver is a very rare presentation of echinococcosis. Only 2 cases have been reported to date $[6,7]$. There is no doubt that the ideal treatment of a cystic or solid mass is total excision. However, this choice is quite aggressive and rarely possible in hydatid cysts of the liver, and partial excision of the (peri)cyst with or without omentoplasty usually results in a better clinical response [15], while radical resections are still the treatment of choice for hepatic hydatid disease [16]. Unlike in hepatic hydatid cysts, total excision is technically easier for intra-abdominal nonhepatic hydatid cysts involving the omentam or free peritoneal cysts [17]. The present case was treated by performing a total cystectomy.

Surgery for hydatid cysts is rarely accompanied by an unrelated abdominal surgery. Generally, surgeons are not willing to add an extra surgical procedure during a hydatid cyst operation because of its unclean nature. In our case, the hydatid cyst of the round ligament was totally excised without any spillage and no risk of infection was added to the elective urological procedure. Interestingly, a palpable abdominal lesion made it possible to diagnose and treat a hidden urinary pathology in an early stage. A Medline search found several reports using the keywords "ureteral obstruction" and "hydatid", but those obstructions were secondary to renal hydatid disease [18]. Moreover, to the best of our knowledge, no reports have been found in the literature describing such a combined surgery.

Medical therapy in the form of benzimidazole carbamates, alone or in combination with praziquantel, has been advocated for the treatment of hydatid disease [19-21]. However, it is generally accepted that systemic albendazole treatment is not an alternative to surgical treatment [22]. Albendazole may be given as an adjuvant to surgery to avoid recurrence and to suppress subcentimetre lesions not visible by ultrasound. Therefore, despite the fact that the first scan for any concomitant cysts was negative and that a total cyst excision was achieved, we put the patient on a prophylactic albendazole regimen with a dose of $2 \times 400 \mathrm{mg} /$ day.

We report here a very rare presentation of hydatid disease that originated from the round ligament of the liver. Hydatid cysts should be considered in the differential diagnosis of intraabdominal masses, particularly in endemic regions or in patients who have emigrated from endemic countries, even when serological tests are negative.

\section{References}

1. Tiseo D et al. Cystic echinococcosis in humans: our clinic experience. Parassitologia, 2004, 46:45-51.

2. Yuksel M et al. Hydatid disease involving some rare locations in the body: a pictorial essay. Korean Journal of Radiology, 2007, 8:531-540.
3. Yildirim M, Erkan N, Vardar E. Hydatid cysts with unusual localizations: diagnostic and treatment dilemmas for surgeons. Annals of Tropical Medicine and Parasitology, 2006, 100:137-142.

4. Kireşi DA et al. Uncommon locations of hydatid cysts. Acta Radiological, 2003, 44:622-636. 
5. Engin G et al. Hydatid disease with unusual localization. European Radiology, 2000, 10:1904-1912.

6. Vadalà $G$ et al. Su un caso di cisti da echinococco del legamento rotondo del fegato. Nota preliminare [A case of echinococcal cyst in the round ligament of the liver: preliminary note]. Minerva Medica, 1985, 76:647-649.

7. Fernández Ballesteros A et al. Quiste hidatidico en el ligamento redondo. Una presentacion excepcional. [Hydatid cyst in the round ligament. An unusual presentation.] Anales de Medicina Interna, 1993, 10:619-620.

8. Moro PL, Gonzalez AE, Gilman RH. Cystic hydatid disease. In: Hunter GW, Strickland GT, Magill AJ, eds. Hunter's Tropical Medicine and Emerging Infectious diseases. Philadelphia, WB Saunders, 2000:866-871.

9. Durakbasa CU et al. An audit on pediatric hydatid disease of uncommon localization: incidence, diagnosis, surgical approach, and outcome. Journal of Pediatric Surgery, 2006, 41:1457-1463.

10. Hamamci EO, Besim H, Korkmaz A. Unusual locations of hydatid disease and surgical approach. ANZ Journal of Surgery, 2004, 74:356-360.

11. Ozoilo KN et al. Anterior abdominal wall hydatid cyst: an unusual presentation. Nigerian Journal of Medicine, 2007, 16:181-182.

12. Moosavi SR, Kermany HK. Epigastric mass due to a hydatid cyst of the pancreas. A case report and review of the literature. Journal of the Pancreas, 2007, 8(2):232-234.

13. WHO Informal Working Group. International classification of ultrasound images in cystic echinococcosis for application in clinical and field epidemiological settings. Acta Tropica, 2003, 85(2):253-261.

14. Gonlugur $\mathrm{U}$ et al. The role of Casoni's skin test and indirect haemagglutination test in the diagnosis of hydatid disease. Parasitology Research, 2005, 97:395-398.

15. Uravic $M$ et al. Diagnosis and treatment of liver hydatid disease. Hepatogastroenterology, 1998, 45:2265-2269.

16. Aydin $\cup$ et al. The optimal treatment of hydatid cyst of the liver: radical surgery with a significant reduced risk of recurrence. Turkish Journal of Gastroenterology, 2008, 19:33-39.

17. Türkyilmaz $\mathbf{Z}$ et al. Conservative surgery for treatment of hydatid cysts in children. World journal of Surgery, 2004, 28:597-601.

18. Yaycioglu $\mathrm{O}$ et al. Isolated renal hydatid disease causing ureteropelvic junction obstruction and massive destruction of kidney parenchyma. Urology, 2006, 67:1290.e15-17.

19. Teggi A, Lastilla MG, De Rosa F. Therapy of human hydatid disease with mebendazole and albendazole. Antimicrobial Agents and Chemotherapy, 1993, 37:1679-1684.

20. Silva MA et al. Treatment of hydatid disease of the liver. Evaluation of a UK experience. Digestive Surgery, 2004, 21:227-233.

21. Koulas SG et al. A fifteen years experience (1988-2003) on the management of liver hydatidosis in northwestern Greece. International Surgery, 2006, 91:112-116.

22. Kapan $\mathrm{S}$ et al. Albendazole is not effective for primary treatment of hepatic hydatid cysts. Journal of Gastrointestinal Surgery, 2008, 12:867-871. 